\title{
Harry R. Moody and Jennifer R. Sasser (2012). Aging: Concepts and Controversies (7th edition). Los Angeles, London, New Delhi, Singapore \& Washington, DC: Sage Publications, $576 \mathrm{pp}$. ISBN 9781452203096 (paperback)
}

\author{
REVIEWED by ANDRZEJ KLIMCZUK*
}

This book is an unconventional introduction to basic gerontological issues. It is authored by Harry R. Moody and Jennifer R. Sasser, who are developing a theory of critical gerontology. Moody is well known for, among other things, his work with older adult education. He also recently retired as Vice President and Director of Academic Affairs for AARP in Washington, DC. In the seventh edition of Aging: Concepts and Controversies, he extended opportunity to work on the book as a co-author to Sasser, who works as a Chair and Associate Professor in the Department of Human Sciences at Marylhurst University in Portland, Oregon.

One of the goals of the Aging: Concepts and Controversies is to encourage the reader to think critically about the aging population and socioeconomic issues related to this process, instead of just reporting facts, concepts, and theories. The book also emphasizes an interdisciplinary approach to gerontology, through referring to findings in other fields such as sociology, philosophy, biology, psychology, and economics as well as to public debates. This mix is also reflected in the presentations of practical case studies and the sections "Focus on the Future," "Global Perspective," and

*Andrzej Klimczuk, Warsaw School of Economics, Warszawa, Poland 
International Journal of Ageing and Later Life

"Urban Legends of Aging." In addition, there are exercises for writing, reflection, and debate to foster thinking about ethical and political dilemmas related to aging.

The book consists of three main parts that discuss basic concepts related to (1) a life course perspective on aging, (2) health care issues, and (3) socioeconomic issues. Each of these parts begins with an overview of related theories and data, and then further discusses three to five controversies related to each theme.

All of the twelve controversies or debates in this book do not have a clear "right" answer but are an aid to reflection. They discuss topics and dilemmas regarding older people such as the meaning of old age, the decline of intellectual functioning (including loss of creativity and learning), distribution of health care, protection of older people from bad choices (including elder abuse and neglect), death and dying (including depression and suicide, assisted dying), social security and retirement, aging boomers, and the new aging marketplace (silver industries and silver economy). Each controversy is supplemented by four to six relevant original readings with differing viewpoints. In total, the volume includes excerpts from 53 readings with arguments and counterarguments. The book also contains a student guide for doing research for a term paper in gerontology, a list of important resources on aging, and web-based appendix with an Instructor Site (includes test bank, PowerPoint slides, sample course syllabus) and a Student Study Site (video resources, quizzes, links to websites).

Comprehensive sets of pedagogical features and original organizational approach are the main strengths of this book. Although the book provides a large amount of material, it is also very accessible and fosters reflection on thought-provoking questions. However, the authors did not succeed in using a more narrative, non-polemical tone to contrast with the provocative tone of the readings. As representatives of critical gerontology they, more than the authors of the readings, focus on constructions of aging and the search for a more positive vision of old age and the future of aging. Nevertheless, in using the book for classroom discussion, this added perspective by the authors also makes the book more interesting. Aging: Concepts and Controversies may be particularly useful in a class discussion where students can contribute their opinions based on the original 
readings from differing perspectives. It is also possible to divide students into small groups during exercises and term paper writing to identify the main issues and points in the readings.

It should be noted that Moody and Sasser mainly focus on issues in the United States. Thus, the book contains basic concepts that may be less interesting for readers in other parts of the world. The US-based data and research on health care and social security may be less useful to a non-American readership. Nevertheless, the described controversies may be considered relevant for a wider international readership as these issues often constitute a taboo and need more local research. This book could thus encourage a more open debate on sensitive issues in classrooms, even outside the United States. Moreover, to those interested in comparative studies, the chapters on analyzing the public policy on aging, the economics of aging, ethical issues, and biases in health and social policies in terms of social class, gender, race, and ethnicity as well as multiple discrimination may be inspiring. The additional value of the future editions may be the use of international and cross-cultural perspectives, materials, readings, comparisons, and practices in non-industrialized countries.

Although this book was written primarily as a textbook for students it could be particularly interesting for scholars focusing on the sociology of aging, the economics of aging, ethics, and health policy who are searching for new or less explored ideas in their countries or regions. It may also be a useful addition to a social gerontology course outside the United States. However, as this book refers to difficult issues and to a significant amount of material, it is rather more suitable for upper-level undergraduates or introductory-level graduates. First-time gerontology students may have difficulties discussing and writing about the controversies. For students new to gerontology, the use of this book should also be complemented by the readings on basic gerontological concepts and theories. Aging: Concepts and Controversies definitely encourages critical thinking and may encourage readers' interest in gerontology. 